\title{
Online Access to Legal Doctrine
}

Jules Winterton

\section{Introduction}

This chapter discusses the evolution of online access to legal doctrine and some of the factors underlying the writing, production and dissemination of legal doctrine in England and Wales with some reference to the USA. This involves a brief discussion of legal doctrine in the context of scholarly legal writing, the nature of the communities which primarily produce the legal writing classed as doctrine and the drivers for their behaviour. It also takes into account the nature of the ongoing transition from print production and distribution to online availability in a wide variety of models. "The term 'legal doctrine' refers ... to the activity of scholars as well as to the products of this activity, that is, to the content of books and research. My original intention was to write about the products rather than about the activity. But an understanding of the products very often requires reference to the activity" (Pattaro 2005, 1).

Aspects of this discussion will naturally be applicable to other countries especially in an era of internationalisation. However, although aspects of the means of publication and the platforms available for dissemination, the experience of scholars and publishers, and indeed some aspects of law itself have become more similar across countries, one must not assume that an analysis of factors for one jurisdiction can lead one to conclusions for others (Cownie 2004, 25).

\section{Scholarly Legal Writing}

In the context of this chapter, written legal 'doctrine' has been taken to signify writing by legal scholars, primarily academic legal scholars, which records research into or thinking about, comments on, analyses, critically discusses, seeks to interpret, explain, compare and even influence the shape of the law, the legal system and all that pertains to it.

The boundaries between formal and informal forms of written scholarly communication have become less rigid in the era of online access; preprints and non-final versions of papers have become more widely available and even blogs and email discussions, not discussed in the chapter, may be preserved (Plotin 2009, 53).

In England and Wales this scholarly writing is generally termed 'secondary literature'. To address the question of definition by exclusion, for our purposes, scholarly writing does not include the primary literature: statutes and regulations (themselves called primary legislation and secondary legislation), the law reports, albeit they may contain scholarly exposition of points of law, nor does it include formal documents of law issued by the government including the text of constitutional documents and treaties. So this chapter does not extend to discussion of the 'freeing of the law' in various jurisdictions by the provision of free access to judgments or decisions of courts and tribunals or of the text of legislation, where previously access had been restricted by cost and by a narrow perception of the potential readership who would want to read them or even should read them.

The writings of academic legal scholars in the England and Wales have at times been the subject of some criticism and this is relevant to the nature of the writing and the adoption of online modes of publication and, intimately related to online publication, open access publication. The nature of scholarly writing in law in the past has been quite closely aligned with the practising profession and a doctrinal approach to law. "A history of British scholarship during the twentieth century would 
probably omit any mention of legal writing. The dominant ethos within law schools has been to do work which was 'saleable'. Given the relative sizes of the academic and professional markets, that which was saleable was for the legal professions." (Bradney 1992, 14). In describing an imaginary law school, Rutland Law School, in a case study, Twining envisages "...a case exhibiting a sample of recent publications by the Faculty, four slim monographs, about a dozen fat books addressed to the student market (three of which are past their third edition), and a number of offprints with obscure titles which some might think are self-addressed. No room could be found here for rather more lucrative publications such as nutshells (or other student aids), contributions to loose-leaf practitioners' services, and occasional journalism" (Twining 1994, 69). The nature of scholarly writing has changed quite fundamentally over the same period during which online means of publication have become widely available and this has taken place for a variety of interconnected reasons including the opportunities offered by technological development.

\section{Legal Doctrine}

In common law jurisdictions the term doctrine used without qualification broadly refers to a framework of legal rules and procedures or an established rule or principle (Tiller and Cross 2005). Doctrinal writings in all forms of legal literature are those which expound the framework by seeing the bones of principle beneath all the untidiness of law as it is made and applied, or which by analysis seek to develop and extend that framework.

'Doctrine' referring to legal writing may be better understood in some jurisdictions where traditional organs of publication of the law contain legislation, decisions, and 'doctrine' and where such writing has carried rather more persuasive power in the process of decision-making than in the United Kingdom. Guinchard and Montagnier (1998) review the definition of doctrine and discuss the power of French doctrine as a body. Although the nature of doctrinal writing in civil law jurisdictions has been subject to criticism, that it seeks to impose an order where the evidence does not support it, there are analyses which seek to meet those criticisms and to value the process of systematization and interpretation (Peczenit 2001).

In the context of academic scholarly legal writing in England and Wales, 'doctrinal' may imply a rather different meaning. "Traditionally law has been analysed and taught [in English law schools] from a doctrinal or 'black-letter' perspective, which concentrates on examining statutory materials and the reports of judicial decisions as the sole means of understanding the law" (Cownie 2004, 35). Sugarman describes the making of the textbook tradition and the role of jurists in exposition of a common law system where legal doctrine was held out to be or desired to be an internally coherent and unified system of rules if only the correct analysis was applied, albeit the reality is 'shot through with self-contradictions, omissions and absurdities' (Sugarman 1986, 27) although Twining modifies the sense that exposition was ever the overwhelmingly dominant mode of English legal scholarship (Twining 1994, 130-140). The term doctrine or doctrinal still exposes in the UK important debates on the nature and purpose of legal education, summarised by Cownie $(2004,33)$, and when it is applied to legal writing it implies a narrower definition than the definition used in this chapter.

The scope of legal writing in the UK and the research into and teaching of law, has broadened and become more inclusive, interdisciplinary and pluralistic in the past fifty years and this has had an impact on its publication and dissemination and, arguably, the means of publication has had a reflexive effect on its nature.

\section{The Writers}

This paper concentrates on the written research outputs of legal scholars, more particularly legal 
academics and indeed the writings of academic scholars from other disciplines coming to law from different perspectives.

Scholarly writing is of course also produced by those involved in decision-making or the practice of law and may be contained in forms of legal literature other than scholarly writings but they are not affected by all the same drivers for change. The role of practitioners (barristers, traditionally known collectively as the scholarly branch of the profession in England and Wales, and solicitors particularly in areas of international and commercial practice) and the judiciary in the exposition and interpretation and the development of the common law is of course immense. To these should be added the writings of those engaged in the formal process of law reform which at least in recent times have included seconded legal academics and have produced remarkable surveys and comparative analyses of areas of law under investigation.

Although changes in online availability have continued, often not as rapidly as might be expected, the cultural factors of scholarly legal research remain an important dimension. As Plotin argues, the changes (or the relative lack of change at the time in the United States) in scholarly communication in law require an understanding not only of the opportunities afforded by available technology but also of the culture of the discipline, "I will argue that it is necessary to undertake an analysis of the scholarly culture within law to explain why scholarly legal communication has taken the direction it has in the digital age" (Plotin 2009, 32).

The number of law schools, law students, postgraduate programmes and the number of academic lawyers increased at a vigorous rate over recent decades at least until rather recently. The very nature of academic legal culture is in flux with the increased international mobility of academic scholars between countries and between legal systems, the increasingly interdisciplinary nature of legal scholarship as academic lawyers come to recognise the value of other disciplines and adopt their methodologies as part of the move from doctrinal writing, and the impact of initiatives in the scholarly legal agenda such as critical legal studies, socio-legal studies, and empirical legal studies. The culture of law schools in England and their place in the academy has been examined in Legal Academics: culture and identities (Cownie 2004) and a decade earlier in Blackstone's Tower: the English Law School (Twining 1994).

\section{Form and Content}

In a period of transition from the early 1990s, change in the nature of legal scholarship has been facilitated: by the ability of online publications to reach across borders, both national and disciplinary, to create virtual networks much larger than the traditional academic actual networks (Cownie 2004, 153), by the ability to provide the economics of systems with relatively fixed costs in relation to amounts of data compared to print, by the drivers away from writing of a descriptive nature in response to research assessment exercises, and by the emphasis on individual research papers rather than more saleable publication projects such as practitioner handbooks and mass student market textbooks.

There is a case made that there is a reflexive effect and the online medium has not only developed to service the changing needs of legal scholarship but has had an effect of the nature of the scholarship it carries. This is explored in Legal Information and the Development of American Law, a collection of essays inspired by the contribution of Robert Berring to the analysis of legal information and its effect on legal culture and the development of American law. Danner tracks the introduction to legal scholarship of "the idea that the forms in which information is communicated can have as much influence on values and institutions as the substantive content of the information" (Danner 
2008 , 24). Brian Simpson argued that that "certain literary forms are closely tied to theories about the nature of law itself, and that this is particularly true of the treatise" (Simpson 1981, 633).

The diversification of content and readership has gone hand in hand with online access in an age where every access can be counted. Adding a paper to a general database or interlinking for searchability rather than limiting its anticipated audience to 'legal' might add to the access count as well as facilitate a broader approach to legal scholarship. The farce of any limitation to 'legal' literature was identified by Karl Llewellyn (cited in Danner 2008, 36-37) more than fifty years ago and with it the implicit criticism of attempts to understand a legal system within a silo of legal culture. Arguably the increasing availability of 'law-related' materials to lawyers also had an effect on the courts in the US with citation of non-legal materials increasing from around 1990 when nonlegal information became more easily available in the dominant commercial systems, Lexis and Westlaw (Danner 2008, 37-38) and this had an effect even on the practice of the courts in the US (Schauer \& Wise 2000, 495). In the eyes of some, "the very notion of 'legal information' has become an anachronism" (Mersky 2008, 233) and this plays to the territory of the large online interdisciplinary information packages marketed by publishers as well as the changing nature of legal scholarship.

\section{Higher Education Policy}

The changes in the nature of legal scholarship towards diversity, interdisciplinarity and critical analysis may have been hastened by the process of academic management and funding in the UK. The Research Assessment Exercise (RAE) which first took place in 1986 and its successor from 2014 the Research Excellence Framework (REF) attempt to evaluate and quantify the research done at universities and link them to public funding. Although the exercises, their processes and methodologies have been subject to considerable criticism in the UK (Cownie 2004, 135-141 and analysed in a wider international context by Peruginelli 2015), it has also been argued that their effect on research and published research outputs has in some ways been benign (Bradney 2003, 186). In order to meet the requirements of the exercise, there has been more emphasis on published research in refereed academic legal journals or in monographs - although there is a common perception that given the timetables for the exercises and the rules on the number of items to be submitted, shorter pieces are less of a risk than longer projects - and more alignment with the experience of academic research in other disciplines. The exercises discouraged publications generally aimed at the practising profession and the student textbook market, the so-called 'textbook tradition' identified by Sugarman (1986), and the pattern of publication has changed accordingly (Cownie 2004, 200).

Increased audit and accountability and the pressure to meet specific publishing targets as well as the need to find a means of publishing increasing amounts of research which might not appeal to commercial legal publishers went hand in hand with the growth of online publishing by institutions. This was facilitated by the acceptance for some purposes of online publication by the terms of the exercise and latterly by a requirement for open access publication which inevitably meant online publication. In turn the move required and facilitated the growth of repositories, particularly institutional repositories, both to publish but also to service the massive institutional task of auditing and managing information about research outputs.

It is generally understood that open access for monographs is less well-advanced. "In planning an approach for open access and the next REF, the UK higher education funding bodies received very clear advice, during consultation, that the monograph publishing world was not yet at a stage where it could support an open access requirement. We have listened to this advice; monographs and 
other longer publications will not need to be made available in an open access form to be eligible for submission to the next REF" (http://www.hefce.ac.uk/rsrch/oa/monographs/, January 2015). However it is likely to be only a matter of time before 'chapters in books' and monographs themselves will be incorporated into the new requirements.

\section{Evolution of Online Access}

Early full text databases, with law in the vanguard, were originally aimed at access to primary legal materials in order to control and make accessible increasing amounts and increasingly wider scope of decisions and legislative material. The first impact and the continuing major impact has been on primary legal materials rather than the product of academic scholarly writing. Even the need to make revisions to a large and growing body of statute law called for electronic processing at an early stage in technological development (Bing 1984, 257-260). Early investments were experimental, often by government or research institutions. Commercial enterprises developed the systems, being able to make the major investments necessary at the time for large scale technological infrastructure and being already in possession or able to acquire cheaply or without cost the necessary content as a service to legal institutions unable to finance online access themselves.

Early systems tended merely to reproduce what was available in print, using a new delivery system without a new paradigm. Online access evolved "but new technologies do not simply provide more powerful, efficient, and convenient methods for extracting knowledge from traditional sources of legal authority. Instead the new communications technology that connects people across networks may make it possible to identify legal authority from new sources ..." (Katsh \& Noveck 2008, 174). Online format enabled the searching of large bodies of law, drawing in new legal authorities not only from the jurisdiction itself by from further afield. This aligns the development of online legal access with the process of internationalisation of legal norms and legal process and the overall effects of the changes usually gathered up in the term globalisation, including of course the growth of major conglomerate legal publishers.

Are there also implications determined by format for scholarly writing in an online age? The impact of online access was first and is still mainly on access to primary legal materials. Items of primary legal materials tend to be shorter, more focussed and better identified by citation elements than scholarly writing, facilitating noting up and updating. In an age where courts have moved from the insistence on paper submissions to electronic management, there are fewer obstacles to joined-up electronic process.

\section{Advantages and Disadvantages}

Online access has made it technologically possible to shorten the chain of scholarly communication: authorship, editing, proofing, selection and quality control, dissemination, bibliographic control / digital identity, marketing, access / findability, long-term preservation (Danner 2002, 352 and generally on scholarly communication in other disciplines 349-357). Transition to online access changes the roles and responsibilities of the actors in the overall process, subject always to the interests of publishers, the ownership and contractual obligations of content providers, and the ability of new actors to replicate the expertise of the traditional publishers. Online access allows major improvements in some aspects of production, access and use, and costs but demands some long-term investments in editorial and production processes and creates some disadvantages and hidden costs of its own for which in the short to medium term there are no satisfactory alternative solutions. Formerly commercial publishers controlled almost all the editorial, proofing, indexing, production, dissemination, and marketing as well as the management of selection and quality control. Authors of scholarly writing would generally be supplying content at low cost or without 
payment (with the exception of the sort of writing noted above in relation to practitioner or student textbooks which realised considerable income for authors). Libraries generally provided bibliographic control, access / findability, and long-term preservation.

In an era of online access, technology enables the widespread publication of much larger volumes of material, more quickly, meeting the growing need of a larger number of scholars encouraged to be more productive by the funding authorities and producing publications for a smaller market. The technology is now affordable by many more publishers, smaller publishers, and not least the institutions employing the scholars. This enables institutions to undertake publication themselves, including dissemination, provision of searchablity and therefore also take responsibility for editing, proofing, selection and quality control. To an extent publishers have already ceded responsibility for these functions to the scholarly content providers; authors are often expected to submit what almost amounts to 'camera-ready' copy, supply an index, and of course peer-review for quality control which has often been an unpaid activity by fellow scholars.

If the key elements of scholarly communication, dissemination and preservation, are addressed in the development of online access, preservation is sometimes given less immediate attention. Responsibility for the vital long-term preservation, persistence of access, and bibliographic control / digital identity must now lay early in the chain of communication with the originator or the publisher, where they are different, rather than at the end of the chain, since the final product is no longer owned by a wide variety of libraries reducing the risk of losing content. However, preservation is far more burdensome, if it is done properly, since it involves a long-term continuing commitment by a wide variety of providers and may involve a moving target of updated material. This involves companies whose economic interests may intervene and companies which fail or change their business strategy. National and research libraries have struggled to cope with a viable strategy for electronic preservation or electronic copyright deposit to fill the gap, a role they fulfil on a coordinated national basis for print publications.

Questions of authenticity and version control are also more prominent in online forms of publication. When there is less likely to be one final and fixed version and when several amended, revised or adapted versions exist both in 'pre-published' and published versions from different sources, version control becomes more important and can be overlooked, citation becomes more complex, and authenticity comes into question.

The nature of the searching also changed with the advent of online access: it is easier in full text online systems to search for facts not concepts. Online access and information retrieval suited access to discrete and structured pieces of text rather more than access to scholarly writing, the socalled passive use of information systems (Bing 1984, 132). There still seems to be no full substitute for investing in human resource for indexing legal concepts despite considerable advances in the automated analysis of text. Low cost repositories often do not provide full-text searching or sufficient investment in metadata.

As more aspects of publication have been taken into the hands of organisations which are not traditional publishers, there has been a danger that the process is technology-driven. The dramatic fall in the cost of technology and its availability and relative ease of use, the elimination of costs of production, warehousing and distribution may have led new publishers to fail to acknowledge the costs of other processes such as editorial, quality control and marketing. However, some of these processes have already been substantially transferred by some commercial publishers to authors and their institutions. Authors are often required to find the capacity within their organisation to copy edit, format, index, and generally prepare text for publication. Peer review of articles has traditionally been provided by scholars without payment. At least in theory some capacity at the 
source, the content provider, for these processes has been established. Even so there remain hidden costs, for example in the administration of peer review, aside from academic time (Times Higher $25^{\text {th }}$ February 2016, 'Less than an hour for peer review admin') and in marketing, an area where open access publishing has not yet excelled. As universities are driven to account for academic time more narrowly, the full economic costs of the full publication process are being recognised. Despite the new entrants to the market with new and successful models of dissemination, it is proving necessary to reinvent in a sustainable form at least some of the unseen activities of traditional publishers and absorb those hidden costs.

The model for traditional print publication had been breaking for some years. In some subjects prices for print journals are very high and inflating at a rate the scholarly sector cannot afford. As prices rise, the market shrinks and in a rather strange economic model prices then rise to cover fixed costs or desired levels of profitability (often benchmarked by other sectors of the publishing business either professional or entertainment). This relies on a core market assumed to be captive and on unique content. It leads to an absurd a situation where the funders of institutions are involved at the same time in efforts to ensure that universities are encouraged to produce more research outputs, traditionally supplied to publishers at little or no cost, while at the same time finding themselves unable to fund universities to buy the published content. This in turn limits access to knowledge and sustainable development. The movement for open access publication of research is closely linked to online access, given this crisis in scholarly communication and the availability of online means of publication.

\section{Open Access and Legal Scholarship}

The move to open access is a development driven by motives to enhance access to knowledge, particularly through the publication of research paid for from public or charitable funds, and it is linked both in time and in economic terms to availability of online means of publication. Although one can discuss open access in terms of technological possibilities, economic models and drivers for academic endeavour, one should not lose sight of the altruistic nature of the open access movement to share knowledge and speed up the pace of research and development. There have been initiatives at WIPO, the World Intellectual Property Organisation, regarding access to knowledge and the purpose of copyright, where a development agenda has been brought forward over the past decade (http://www.wipo.int/ip-development/en/agenda/background.html) and a development agenda at the United Nations to which the Lyon Declaration of Access to Information and Development of August 2014 (http://www.lyondeclaration.org/) is addressed. The free international online alerting service Copyright and A2K Issues from the African Legal Information Institute at the University of Witwatersrand (email copyrightanda2kissues@africanlii.org) covers a wide range of related topics including open access, access to knowledge, and scholarly communication.

'Open access' refers to unrestricted, online access to the published findings of research (for an early account of open access principles in the context of legal scholarship see Parker 2007, 5-16). There is an intrinsic link thanks to the relative ease and low cost of the technological elements and the reduced investment needed to publish and disseminate, the existing network infrastructure of universities, and the new uses to which well-developed computer centres can be put. There have been obstacles, now substantially removed, such as the need to meet the requirements for formal recognition of research, for example by the UK's research assessment exercise. In fact there has been positive encouragement by research funding bodies that research should be published in open access in some form and it is now a requirement that certain research outputs submitted to any research assessment exercise after 2014 be made as widely accessible as possible. The Higher Education Funding Council for England (HEFCE) in its role as a national funding body for research believes that all research arising from HEFCE funding should be as widely and freely accessible as the 
available channels for dissemination will allow. In this it has been followed by other major national research funders.

This has led to the various forms of open access publication for various versions of papers including the officially-sanctioned green and gold routes to open access publication, embargoes to allow publishers to gain a return before the content is released on open access or author processing charges (APCs) to pay commercial publishers to make an article immediately available in open access format (Finch 2012). These developments have been driven mainly by the scholarly communications market in science; Bell analyses the possible effects on the legal publications market (Bell 2012).

If the gold route is preferred, we are still in a transition period between paying for journals through subscriptions and paying for publication in journals through author processing charges. However, the model under which money used to pay for subscriptions can be transferred from library budgets to a fund sufficient to pay for publication is flawed. Libraries will continue to purchase journals, whether from overseas publishers, or designed for the practitioner market, or containing some content not available on open access or not immediately available on open access. Difficulties have already arisen for customers including universities and other research establishments of 'double dipping' by commercial publishers which might find themselves in a position where they charge authors (and through them their universities) to publish articles on open access and then also sell content including those articles but not only those articles back to them by subscription. Additional funding will be required from the research funding pot to fund publication. Journals meanwhile will not be able to continue to raise subscription income from other subscribers outside universities if content is available on open access and that funding gap must also be made up from the authors. In effect authors and their higher education institutions will be subsidising use by commercial institutions. Why not rely on institutional or other repositories which do not charge APCs? The main advantage of the traditional journal publication process is selection and quality control and this is why Bell argues that the journal is not dead (Bell 2014).

The green route for open access publication has generally proved more popular as well as more affordable. From April 2016 HEFCE in the UK has made it mandatory for the peer-reviewed versions of articles and conference proceedings to be deposited on an open access platform, which would usually be an institutional repository, in order to be admissible for the next Research Excellence Framework exercise (http://www.hefce.ac.uk/rsrch/oa/). This process would still respect an embargo period under the green open access route and does not require institutions to pay author processing charges.

It seems that merely changing from one funding stream to another for scholarly communication by adopting the UK government's apparent preference for the gold route, which might preserve a commercial market, may only be a temporary solution and the market will encounter more fundamental change.

\section{Repositories of Papers}

When the opportunities offered by technology for online publication were first recognised by universities, services were set up by early adopters to offer publishing or hosting for institutions such as SSRN's Legal Scholarship Network (http://www.ssrn.com/en/index.cfm/lsn/), the Law Commons of 'bepress' originally the Berkeley Electronic Press initiative (http://network.bepress.com/law/), and the law library consortium NELLCO's Legal Scholarship Repository (http://lsr.nellco.org/) and more generally Academia.edu and ResearchGate (Matthews 2016 and see generally papers on open access, digital scholarly communication, and the changing role of research libraries at http://digitalcommons.bepress.com/repository-research/). Such 'self-archiving' of pre-prints or working papers was designed to alert readers to new research findings and find new international and multidisciplinary readerships. The services enabled online publishing, reasonable findability, exposure, marketing and promotion on a discipline or multi-discipline basis. The bringing together of 
collections of papers, pre-prints or non-final versions, which were allowed by or did not contravene agreements or assignments of the copyright in final versions to publishers, produced workable economic models and recognised concentrations of research material, drawing in scholars to participate and to search in a way that research libraries have always done.

This type of repository also provides a version of an academic social network, a collegial role allowing not only dissemination but also a much wider facility for feedback, discussion, recommendation and the possibility of changing the nature of peer review. They have developed as platforms to demonstrate the prestige and achievements of institutions, their faculties and individual scholars. They provide far more measurable results than traditional publishing in terms of items found, downloaded and, hopefully, read, and by extrapolation new ways to measure scholarly impact. However, some of this type of repository have been criticised for not adhering to the requirements of standard open access policies and of establishing an alternative system of monetisation of scholarly publishing rather than a new open access ethical publishing system (Adema 2016). "But it is worth noting that law, which has always enjoyed low-cost access to its scholarly literature [in the US] through its institution-based publishing system, could become reliant on commercial services to provide electronic access to new papers at the same time that scholars in other disciplines are looking to technology to create alternative non-commercial means of access to their literatures (Danner 2002, 361).

Institutional-based repositories, which do not exclude posting on other collective repository services have developed massively over the past few years and have become a requirement of a university institution, often developed at low cost using open source software, see http://sparceurope.org/repositories/. In an era when open access is not merely tolerated but required and mechanisms have been elaborated to achieve it without immediately prejudicing the traditional economic model of publication, post-prints (a version after peer-review and editing) or publisher-print (final version as published) now appear in repositories. It is easier for institutions to encourage or require the posting of papers on their own repository although even then the culture may be slow to adopt and the number of papers contained in such repositories may still be surprisingly low. An institutional repository enhances the prestige of the institution, it facilitates the work of institutional submissions for research evaluation exercises, facilitates audit and performance assessment as well as meeting the altruistic nature of scholarship and access to knowledge. However, the multitude of individual repositories and the resulting fragmentation of publication of papers has reduced findability despite efforts to provide scope for browsing and cross-searching multiple repositories, emulating the union catalogues of libraries and their long-established international standards. There are evolving standards for interoperability to re-establish searching across the sector to move towards the efficiency of major indexing services in print environment.

\section{Journals}

There has been much slower conversion of existing law journals to open access publication in the UK than in areas of scientific research. Old models are still in existence and print journals in law will remain for longer than many predicted. In the UK the major peer-reviewed law journals, while they may have an association with a prestigious law faculty, have been published by commercial publishers for many years. These journals continue to be published in print but many have also been incorporated into commercial databases, usually one or other of the main online subscription databases leading institutions to subscribe to both the competing services. Later commercial entrants building a stable of journals have often opted for a proprietary access systems. This fragmentation of online hosts militates against ease of use and speedy retrieval. It tends to throw emphasis on meta-search engines provided by library services as a single search option, if they are allowed to penetrate the database structure. The fragmentation tends to reinforce the process of depositing a version of the paper in a repository, either as a pre-print or through one of the 
acknowledged open access routes, to reach a wider readership which may not have access to expensive specialist databases or to those libraries which negotiate and buy access to those databases.

There are relatively few electronic-only open access scholarly legal journals and they have been mainly launched as individual initiatives of enthusiastic academics and institutions such as the longrunning refereed European Journal of Law and Technology, formerly the Journal of Law and Technology (http://ejlt.org//index). Unlike in the US, student law reviews in the UK are slighter and do not represent main vehicles for the publication of research outputs. This compares to the relatively enthusiastic adoption of forms of online publication outside traditional journal publication such as repositories discussed above.

Law reviews have been relatively inexpensive in the US where they are major vehicles for legal scholarship (Danner 2002, 347 and generally on scholarly communication in other disciplines 349357) and the major commercial publishers have played a much less prominent role than in the UK in this part of the market. Law reviews form an integral part of the law school experience and are numerous and voluminous and the costs are subsidised by the law schools. In themselves their existence is not threatened by author self-archiving but the crisis in scholarly communication has also affected these law reviews as the sheer scale of publication and distribution, delays in publication and costs grew. However, as they are published by the law schools themselves, there was an opportunity to move to open access publication as the economics of publication changed with the adoption of online access (Litman 2006). The Durham Statement by law library directors of twelve top law schools in the US in 2008 called on law reviews to begin to publish in 'stable, open, digital formats' (https://cyber.law.harvard.edu/publications/durhamstatement). Since then considerable progress has been made (Danner, Leong and Miller 2011) but there have been arguments for the continuation of print mainly accompanied by concerns for preservation (Leary 2011).

The Law Review Commons (http://lawreviewcommons.com/about.html) claims to be the largest collection of free and open and searchable law review scholarship (that is to say articles in law reviews rather than independent papers). As it explains on its website, publishing on open access increases the visibility of legal scholarship, makes scholars' work more discoverable, and may also lead to more citations. It claims that recent analysis found that citation growth rates of open access journals were 3.8 times higher than for comparable non-open access journals in 2012. A detailed US survey published in 2015 addresses citation when a law review article is placed on open access and compares the different profiles of downloads over time between institutional repositories and SSRN: "When looking at citation by other law reviews to all the author's work, the averaged increase in citations in flagship journals is $53 \%$. In general, half of these cites will be dispensed in the first six years after the article's publication. OA articles will attract more attention earlier in the lifecycle of the publication, and endure longer on the intellectual stage. ... For authors, the message is clear: The open access advantage is real, sizable, and consistent. The minimal effort to upload an article onto an OA platform such as SSRN or a school's repository pays rich dividends in the currency of subsequent citations in law reviews and court decisions." (Donovan, Watson and Osborne 2015, 1920 and 21).

Unique players in the market in the US have been the reprint agents which maintained large warehouses and later print on demand to maintain the availability in print of runs of very large numbers of journals, mainly US law reviews. Hein Online is the digital development of these services and, despite the availability of a large number of open access routes to an increasing amount of content, is extremely popular and demonstrates there is a market for a reliable one-stop 
subscription source for a very wide range of journals with a single interface and full-text searching. It is affected by the concerns of some journals which need to retain subscription income and which embargo their most recent volume on the service. Such embargos are likely to be unsustainable over time.

\section{Books}

There were traditionally only a small number of specialist law publishers in England and Wales and they naturally concentrated their efforts on the more profitable and larger practitioner market. In fact 'for considerable periods of its history the common law system produced hardly any treatises at all' (Simpson 1981, 634). The history of the legal treatise in the common law world is examined in seminal articles by Simpson (1981) and Sugarman (1986) and the more recent changes in the general nature of writing by legal academics in England Wales have been noted above.

Although in terms of books, major legal publishers have adopted online access, there has been a concentration on the reliably profitable handbooks for practice, usually joined to the major online services for primary materials, and on transferring to online access those services which require frequent updating and which had developed into loose-leaf format books. Ebook format should allow libraries to solve issues of multiple access and the limitations of the physical form in terms of location. However, even where agents are employed to aggregate ebook content, there is still limited choice, difficult and sometimes prohibitive pricing models, differing access software, and little provision for long-term preservation.

There seems to have been a recent relative decline in the publication of monographs by major commercial legal publishers as they bring more of their output in-house. The withdrawal of major commercial publishers, their increasing lack of engagement with younger scholars, and the increase in the production of scholarly work and the ease of online delivery has left market territory for smaller specialist legal publishers but has also opened up opportunities for institutions to move into the publication of research monographs themselves.

Some universities have of course operated university presses, some with a very long tradition, to make available the products of their research and the research of others, even though there has not been in England and Wales the same tradition of the publication of theses as in continental universities. Even some of these publishers have needed to modify their editorial policy to become more financially self-sufficient. The largest have adopted proprietary platforms for the online delivery of packages of books, for example Oxford Scholarship Online.

The online delivery of monographs is at an earlier stage than for papers or journals as acknowledged by the research funding bodies (http://sparceurope.org/oa-books/). Models for access to ebooks, whether commercial or on a smaller scale open access, which rely on advance subscription payment for a selection of or package of titles struggle in the face of the individuality of monographs and the sheer choice available in print. The paradigm of a 'package' of monographs militates against the process of building a research collection. There is open source software available, for example the Open Monograph Press software platform https://pkp.sfu.ca/omp/ and an increasing number of small individual implementations with a variety of economic models in a range of disciplines.

\section{Future}

The implications of the adoption of online access for the various actors in the process will play out over a considerable time. Content providers are likely to have greater control over the dissemination of their work but adopt wider collaborative and interdisciplinary approaches; publishers will use 
their expertise within the new models of income generation and monetisation; and library and information managers will be well-placed to expand their role in managing a wider range of information resources, projects and budgets, in research skills training and research collaboration, in metadata, and in coordinated preservation strategies (Danner, Kauffman and Palfrey 2009). Despite direct delivery of online data to the researcher, the reduced physical space of most research libraries will continue to be a crossroads for scholarly interaction if active research engagement strategies are adopted.

The future no doubt holds the promise of resolving the challenges presented by the transition to online access to legal scholarly writing because, although there are major advantages, not all aspects of scholarly communication have yet been improved. There are continuing tensions - between competing commercial copyright owners, between proprietary systems and international standardisation, between individual initiatives and slower international agreements regarding interoperability, between commercial interests and the scholarly sector, between dissemination and preservation. There will need to be a new and continuing accommodations between the commercial and the academic sector and a further commitment to collaboration among individual institutions with their fragmented and multi-speed adoption of online open access means of delivery of scholarly writing. It is likely that there will be no one model that will synthesize the various different aims of speed, quality, open access, and long-term preservation. It is also likely that, while the sector might offer ways to provide online hosting, this will increasingly have to take account of the real and hitherto hidden costs of editing, peer reviewing, production and all the other aspects of scholarly communication provided in the past through either 'free academic time' or costs subsumed in subscription prices. It is also likely that many of the deconstructed processes of commercial publishing will be reinvented by the sector or be retained or remerged into commercial operations. The temporary settlement of green and gold open access will not stand the test of time and will need to be renegotiated as cost models change under the pressure of technical capacity, actual usage, and the realities of successful publishing.

\section{References}

Adema, J. (2016), 'Responsible enterprise: don't give commercial operations free labour' [note], Times Higher Education 7 April 2016, 44.

Atchison, A. and Bull, J. (2015), 'Will Open Access Get Me Cited? An Analysis of the Efficacy of Open Access Publishing in Political Science, 48 PS: Political Science \& Politics 129-137. Research on Institutional Repositories: Articles and Presentations, Paper 87. http://digitalcommons.bepress.com/repository-research/87

Bell, J. (2012), 'The Future of Legal Research', 12 Legal Information Management, 314-317.

Bell, J. (2014), 'Open Access: the journal is not dead!', 14 Legal Information Management 143-145.

Berring, R. (2000), 'Legal information and the search for cognitive authority', 88 California Law Review, 1673-1708.

Bing, J. ed. (1984), Handbook of Legal Information Retrieval. Amsterdam: North-Holland.

Bradney, A. (1992), 'Ivory Towers and Satanic Mills: choices for university law schools', Studies in Higher Education, 5-20.

Cownie, F. (2004), Legal Academics: culture and identities. Oxford: Hart. 
Danner, R. (2002), 'Electronic Publication of Legal Scholarship: new issues and new models', 52 Journal of Legal Education, 347-364.

Danner, R. (2008), 'Legal Information and the Development of American Law: writings on the form and structure of the published law' In Danner and Houdek (2008), 6-56.

Danner, R., and Houdek, F., eds (2008), Legal Information and the Development of American Law. St Paul MN: Thomson West.

Danner, R., Kauffman, S. and Palfrey, J. (2009), 'The twenty-first century law library', 101 Law Library Journal 143-156.

Danner, R., Leong, K. and Miller, W. (2011), 'The Durham Statement two years later: open access in the law school environment', 103 Law Library Journal 39-54.

Donovan, J., Watson, C. and Osborne, C. (2015), 'The open access advantage for American law reviews', Journal of the Patent and Trademark Office Society Edison 2015-03A, 1-22, at http://www.jptos.org/uploads/edison/edison2015-03A.pdf

Finch, J. (2012), Accessibility, sustainability, excellence: how to expand access to research publications: report of the Working Group on Expanding Access to Published Research Findings. London: Research Information Network. http://www.researchinfonet.org/wpcontent/uploads/2012/06//Finch-Group-report-FINAL-VERSION.pdf

Guinchard, S. and Montagnier, G. (1998), 'The Entity of French Doctrine: some thoughts on the community of French legal writers', 18 Legal Studies 414-437.

Katsh, E. and Noveck, B. (2008), 'Peer to peer meets the world of legal information: encountering a new paradigm'. In Danner \& Houdek (2008) 174-187.

Leary, M. (2011), 'A response to The Durham Statement two years later', 103 Law Library Journal 281-286.

Litman, J. (2006), 'The economics of open access law publishing', 10 Lewis \& Clark Law Review 779795.

Matthews, D. (2016), 'Does your research need 'likes'?'. Times Higher Education 7 April 2016, 41-45.

Mersky, R. (2008), 'Legal Research versus Legal Writing within the Law School Curriculum', In Danner and Houdek (2008), 233-240.

Parker, C. (2007), 'Institutional Repositories and the Principle of Open Access: Changing the Way We Think About Legal Scholarship', 37 New Mexico Law Review 1-46 and Research on Institutional Repositories: Articles and Presentations. Paper 56. http://digitalcommons.bepress.com/repositoryresearch/56

Pattaro, E. (2005), A Treatise of Legal philosophy and General Jurisprudence, vol.4; Scientia Juris, Legal Doctrine as Knowledge of Law and as a Source of Law. Dordrecht: Springer.

Peczenit, A. (2001), 'A Theory of Legal Doctrine', 14 Ratio Juris 75-105, http://onlinelibrary.wiley.com/doi/10.1111/1467-9337.00173/pdf

Peruginelli, G. (2015), 'Evaluating research: the case of legal scholarly outputs', 15 Legal Information Management, 50-56. 
Plotin, S. (2009), 'Legal Scholarship, electronic publishing and open access: transformation or stagnation?', 101 Law Library Journal 31-57.

Schauer, F. and Wise, V. (2000), 'Nonlegal information and the delegalisation of law', 29 Journal of Legal Studies 495-515.

Simpson, A. (1981), 'The rise and fall of the legal treatise: legal principles and the forms of legal literature', 48 University of Chicago Law Review 632-679.

Sugarman, D. (1986), 'Legal theory, the common law mind and the making of the textbook tradition' in Twining (1986), 26-61.

Tiller, E. and Cross, F. (2005), 'What is legal doctrine?', Public Law and Legal Theory Papers, Working Paper 41, http://law.bepress.com/nwwps-plltp/art41/.

Twining, W. ed. (1986), Legal Theory and Common Law. Oxford: Blackwell.

Twining, W. (1994), Blackstone's Tower: the English law school. (Hamlyn Lectures, $46^{\text {th }}$ series). London: Sweet \& Maxwell. 